Revue d'histoire de l'enfance " irrégulière »

Le Temps de l'histoire

$11 \mid 2009$

Paroles libres, paroles captives

\title{
Nathalie Brémand, Les socialismes et l'enfance.
}

Jean-Claude Caron

\section{(2) OpenEdition}

Journals

Édition électronique

URL : http://journals.openedition.org/rhei/3107

DOI : 10.4000/rhei.3107

ISBN : 978-2-7535-1650-2

ISSN : 1777-540X

Éditeur

Presses universitaires de Rennes

Édition imprimée

Date de publication : 1 octobre 2009

ISBN : 978-2-7535-0927-6

ISSN : 1287-2431

Référence électronique

Jean-Claude Caron, « Nathalie Brémand, Les socialismes et l'enfance. », Revue d'histoire de l'enfance " irrégulière » [En ligne], 11 | 2009, mis en ligne le 01 octobre 2009, consulté le 04 décembre 2020. URL http://journals.openedition.org/rhei/3107 ; DOI : https://doi.org/10.4000/rhei.3107

Ce document a été généré automatiquement le 4 décembre 2020

(C) PUR 


\title{
Nathalie Brémand, Les socialismes et l'enfance.
}

\author{
Jean-Claude Caron
} se distingue par l'importance du thème qu'il traite. On peut d'ailleurs s'étonner qu'il ait fallu attendre si longtemps pour qu'un travail universitaire s'attaquât à la passionnante question des relations entre les socialismes et l'enfance. Nathalie Brémand s'est donc emparé avec bonheur d'un thème dont elle justifie les limites chronologiques (même si la Commune se trouve de ce fait exclue). Il ne s'agit pas pour elle d'aborder la seule question de l'instruction au sens scolaire du terme - un point qui est néanmoins abondamment traité -, mais d'envisager tous les aspects des systèmes éducatifs mis en place par ces réformateurs sociaux.

6 La première partie de l'ouvrage aborde de manière générale, en une centaine de pages, la place de l'enfant dans les projets de société des socialistes dits utopiques. Nathalie Brémand y rappelle de manière probante l'étonnante prolixité de ces penseurs (mais aussi de simples ouvriers, moins passés à la postérité) sur la question de l'éducation de l'enfant, véritable enjeu dans la perspective du succès de leurs doctrines. Il existe trois grands modèles éducatifs (communautaire, réformateur ou étatiste, familial) qui s'opposent dans leurs modes d'action comme dans leur approche de l'enfant: la question des droits de ce dernier se heurte parfois à celle de l'autorité paternelle et plus largement à l'institution de la famille. L'une comme l'autre sont soumises à des réinterprétations différentes, mais, plus encore, c'est le lien éducatif entre mère et enfant qui apparaît au cœur du débat.

7 Parmi les aspects étudiés par l'auteur, on remarque la question de l'espace infantile et du mobilier, au sein de la maison familiale, de la communauté ou de l'école ; mais aussi 
la question du genre, celle des enfants déviants, ou encore celle de la discipline. L'enfant envisagé par les réformateurs sociaux n'est pas qu'un élève : il est aussi un producteur en puissance, soumis à un éloge permanent du travail comme seule activité anoblissante et, plus encore, utile. Pour la plupart de ces penseurs, l'enfant doit le plus précocement possible rendre à la société ce que celle-ci a dépensé pour son éducation. Si l'on a parfois le sentiment d'un passage en revue, pour chaque thème, des positions de chaque penseur, Nathalie Brémand sait toutefois personnaliser son étude en fonction de thèmes spécifiques - on verra ainsi la position de Fourier sur la discipline et son opposition entre " petites bandes » et " petites hordes ».

8 La deuxième partie étudie un ensemble d'expérimentations sociales, au cœur desquelles la place et le statut - on pourrait presque dire la considération - des enfants est variable. Le phalanstérion - ou phalanstère enfantin - fouriériste est resté à l'état de projet, aucun n'ayant été réalisé. Intéressant, mais fugace, est l'Institut de l'enfance de Désiré et Jules Gay, installé à Chatillon en 1840. Plus durables sont la Maison de santé et de sevrage de Beauregard (1852-1868), installée près de Vienne, la Maison rurale d'enfants pour l'expérimentation sociétaire, située à Ry (Seine-Inférieure), entre 1862 et 1884 , les communautés familiales comme celle installée par Pierre Leroux à Boussac, ou encore le phalanstère de Cîteaux. Mais l'échec sanctionne généralement ces expériences métropolitaines comme il sanctionne deux expériences brésiliennes, une expérience algérienne et l'expérience emblématique de Réunion au Texas, où Considerant s'opposa à l'ouverture d'une école. Le manque de viabilité économique et la croissance de dissensions internes font imploser ces communautés fouriéristes au sein desquelles, du reste, la question de l'éducation des enfants ne constitue qu'un des aspects de ces expériences, et pas le mieux documenté, ce qui ne permet pas toujours à l'auteure de pousser l'analyse aussi loin qu'elle le désirerait.

9 Après les expériences fouriéristes, Nathalie Brémand étudie les expériences icariennes aux Etats-Unis, entre 1848 et 1895. Mieux documentée, à la fois grâce aux sources primaires et aux souvenirs et témoignages d'adultes ayant vécu leur enfance dans ces communautés, cette partie se révèle passionnante dans ce qu'elle donne à voir de l'éducation du "petit communiste ». Cette dernière, qui en théorie ne relève que de la communauté et aucunement de la famille, y occupe une place importante, même si les icariens eurent aussi recours aux écoles publiques locales. Entre autres points abordés, signalons la question des sanctions, la vie en internat, l'éducation collective, le travail, etc. Dernière expérience étudiée, le familistère de Guise de Godin, de 1859 à 1880. D'inspiration fouriériste, cette expérience de vie communautaire se signale par l'intérêt, alors encore peu fréquent, porté au nourrisson et au petit enfant, avec la mise en place d'une "nourricerie", de la naissance à l'âge de 26 ou 28 mois, d'un " pouponnat » jusqu'à quatre ans et d'un «bambinat » de quatre à six ans. Dans cette communauté sans église qui se veut laïque, et qui tente - non sans mal du fait des menaces administratives qui planent - de limiter l'enseignement religieux, la seule religion tolérée est celle du travail. Nathalie Brémand insiste à juste titre sur les innovations en matière d'hygiène et sur le rôle bien connu de l'architecture du familistère.

10 Ce travail, très convaincant, aurait encore gagné en intérêt en offrant davantage de contrepoints par l'exposé, même succinct, d'autres approches pédagogiques et éducatives, qu'elles proviennent d'ecclésiastiques (Mgr Dupanloup) ou de laïcs (Laprade). On pense aussi au Michelet de Nos fils et à cette pensée républicaine qui 
devait s'affirmer après 1871 dans un certain nombre de réalisations, mais qui fut largement débattue dans la période étudiée par Nathalie Brémand. On regrettera également la trop faible place laissée à l'influence des pédagogues helvétiques et allemands. Enfin, si les scories persistantes sont assez rares (USA pour Etats-Unis !), il est dommage que Considerant soit systématiquement orthographié Considérant, lui qui, sa vie durant, se battit pour faire admettre l'absence d'accent dans son nom... Mais au final, les questions abordées dans cet ouvrage ne sont pas minces et, sans qu'il soit nécessaire de forcer la chose, résonnent d'une actualité évidente. On y perçoit la rivalité entre deux institutions (la famille et l'école) pour le contrôle de l'éducation de l'enfant. Qui peut prétendre que le débat est clos? 